\title{
Photonics workforce education and development in Puerto Rico
}

J. Friedman, A. Diaz, E. Trujillo, R. Saltares, L. Floran, et al.

J. S. Friedman, A. Diaz, E. Trujillo, R. Saltares, L. Floran, R. Gordillo, "Photonics workforce education and development in Puerto Rico," Proc. SPIE 9946, Optics Education and Outreach IV, 99460K (27 September 2016); doi: $10.1117 / 12.2238083$

SPIE Event: SPIE Optical Engineering + Applications, 2016, San Diego, California, United States 


\title{
Photonics Workforce Education and Development in Puerto Rico
}

\author{
J. S. Friedman ${ }^{1}$, A. Diaz, E. Trujillo, R. Saltares, L. Floran, and R. Gordillo
}

Puerto Rico Photonics Institute, School of Environmental Affairs, Universidad Metropolitana, 1399

Ana G. Mendez Ave., San Juan, P.R. 00926-2602

\begin{abstract}
At the Puerto Rico Photonics Institute we have responded to the need of a workforce competitively prepared for entry into the fields of lasers and photonics by creating a 1-year Photonics \& Lasers Technical certificate, supported under a grant from the US Department of Labor. The project, entitled New Horizons: Puerto Rico Lasers and Photonics Career Pathways offers displaced workers, veterans, and others in Puerto Rico an opportunity to develop new and highlymarketable skills for the 21 st century. We give a roadmap of plans and pitfalls, and share our successes, challenges, solutions, and future expectations for those planning similar programs.
\end{abstract}

Keywords: Photonics Education, Workforce Development, Technical Certificate, National Photonics Initiative, PostSecondary Education, Puerto Rico, Photonics

\section{INTRODUCTION}

Rapid progress in the application of light to development of new technologies has created a vacuum in the population of well-prepared scientists, engineers, and technicians. The International Year of Light, in 2015, underscored the need for more awareness of and interest in light-based technologies. Demands in computing and data, communications, medical technologies, lighting and energy efficiency, defense and security, and many other fields have pushed technology development to where the photon is the natural carrier of energy and information, replacing the electron. Yet most technical education programs are not keeping up with the need for their programs to prepare a workforce specialized in, or even familiar with the technologies that are employed.

In 2005, the National Science Foundation's Advanced Technological Education (NSF-ATE) program awarded a 5-year Cooperative Agreement to Center for Occupational Research and Development (CORD) to create OP-TEC, the National Center for Optics and Photonics Education. This cooperative agreement, now managed by the University of Central Florida (UCF), led to the development of standard technical education materials in direct consultation with industries in photonics and those for whom photonics is enabling technology. It also led to the building of a consortium of community colleges, technical colleges, and universities that offer photonics technical certificates and degrees, which now consists of just under 40 members, the OP-TEC Coordinators Network (OPCN). OP-TEC, with input from the OPCN, has built a standard curriculum for technical training and education in photonics.

Latinos, and particularly Latina women are traditionally under-represented in STEM fields [1]. The population of Puerto Rico is virtually all Latino and citizens of the United States, but at the same time, there is a very high level of economic hardship, with $45 \%$ of the population living below the poverty line and nearly all young people requiring federal and other financial aid to attend college. Women represent a solid proportion of students, and there is a large community of military veterans. In spite of the notable disadvantage and economic hardship, Puerto Rico has a solid higher education system and the raw materials for a solid education system at all levels.

The Puerto Rico Photonics Institute (PRPI) was founded at the Universidad Metropolitana (UMET) School of Environmental Affairs in 2011 as part of UMET's joining the new management consortium at the Arecibo Observatory (led by SRI International). In 2014, PRPI won a grant from the United States Department of Labor Employment and Training Administration's Trade Adjustment Assistance Community College and Career Training (TAACCCT) program, which provided $\$ 2.5 \mathrm{M}$ to develop a 1-year workforce training program in photonics. The program, called New

\footnotetext{
${ }^{1}$ jsfriedman@suagm.edu; phone 1787 766-1717 x6617; http://prpi.suagm.edu
} 
Horizons: Puerto Rico Lasers and Photonics Career Pathways ${ }^{2}$, employs a curriculum built on the OP-TEC materials and adapted to knowledge and skillset requirements indicated by industries in Puerto Rico. The curriculum (see Table 1) is a four-quarter program that consists of 40 credits including four optics and photonics technical courses, two electronics technical courses, two electronics technical courses, and one course each of mathematics and English. It includes an innovative course in entrepreneurship, which is intended to both attract people interested in launching small businesses and in awakening the entrepreneurial spirit in students who enter the program for the technical education. Finally, it has an eight-week industry internship during the third of the four terms, which has multiple purposes: direct work experience employing the education in optics, photonics, and electronics; an opportunity for local industry to see potential future employees in a true work environment, and a means for PRPI to receive feedback on the progress of its students and the effectiveness of its curriculum.

\section{NEED}

The PRPI academic programs for a 1-year certificate and associate degree in Photonics and Lasers are directed towards workforce development. As the only institute in PR dedicated to provide training, education, research, and outreach activities in these fields, the decision to develop an academic program responds to the following needs.

First, a national educational need, as expressed by the White House in the National Photonics Initiative in which investments in education, clean energy, and manufacturing will help create jobs and restore middle class security.

Second, a need to prepare a workforce in lasers and photonics, a key enabling technology with an expected worldwide market volume in 2020 of $\$ 820$ billion. As estimated by the National Center for Optics and Photonics Education (OP-TEC), 800+ photonics and optics technician positions go unfilled every year.

Third, a workforce competitively prepared for entry into the fields of lasers and photonics, representing enabling technologies for the aerospace, medical devices, pharmaceutical, and communications industries.

Fourth, needs at the local level:

(1) During the last nine years, Puerto Rico (PR) has experienced economic upheavals that have dramatically impacted the local workforce. According to the Federal Bureau of Labor Statistics (BLS), unemployment has grown from around $10 \%$ to around $15 \%$ and the workforce has fallen by nearly 300,000 (see Figure 1).

(2) Local state plans are focused on and are already expanding the industry base to include those related to lasers and photonics and require a workforce competitively prepared for entry into these fields.

(3) UMET, through the PR Photonics Institute, is the only institution in PR that offers this training. As such, this project meets stated national and local needs and fills an educational void in the pathway to high tech careers for the 21 th century.

We have responded to these challenges by creating a 1-year Photonics \& Lasers Technical Specialist certificate, developed and supported under a grant from the US Department of Labor. The project, entitled New Horizons: Puerto Rico Lasers and Photonics Career Pathways offers displaced workers, veterans, and others in Puerto Rico an opportunity to develop new and highly-marketable skills. The program is intended to impact two particular focus communities while being open to any technically-skilled adult seeking a career in Lasers and Photonics. The first community is those displaced by trade agreements and who are deemed qualified for Trade Adjustment Act (TAA)-eligibility according to the state and local Workforce Investment Act Boards (WIBs), and the second is unemployed or underemployed veterans and reservists. In addition to the technical credential offered by UMET, students will have the opportunity to obtain an internationally-recognized industry credential as a Photonics Technical Operator through ETA-International, taking the qualification exam at PRPI.

\footnotetext{
${ }^{2}$ US DOLETA TAACCCT Round 4 Grant number TC-26472-14-60-A-72
} 


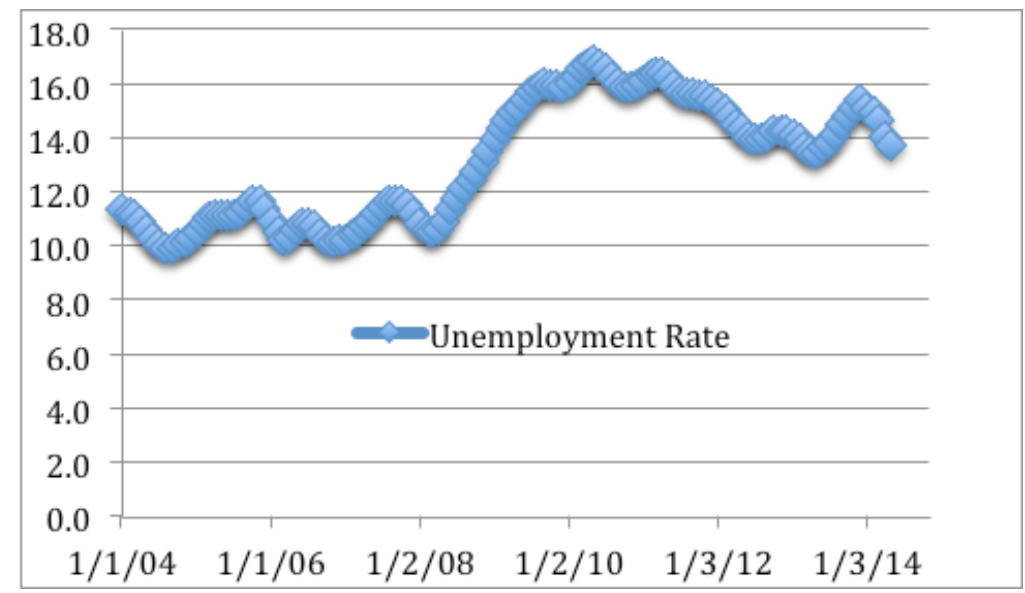

Figure 1. Unemployment rate for Puerto Rico, 2004-2014.

\section{EDUCATIONAL TRAINING PROGRAM}

\subsection{Objectives and Rationale}

Its primary goal is to impact Puerto Rico's workforce through the inclusion of highly-technical and specialized training in lasers, optics, and photonics. The skills acquired by New Horizons participants will be applicable to a wide range of fields, including those mentioned in Section 1.

Much of the curriculum offered through New Horizons is adapted from OP-TEC. The goal of this new program is to prepare photonics systems technicians to work in industries whose processes and operations require the extensive use of lasers and/or optical or photonic devices in order to meet production or mission goals. This usually implies the integration of optical, photonics, or laser subsystems into larger systems, where photonics is an enabling technology.

In alignment with this goal, the proposed certificate program has the following specific objectives:

- Prepare technicians with the knowledge of how photonic devices and lasers operate and interface with the equipment or systems in which they are embedded, and who understand how photonics devices and subsystems enable equipment and systems to accomplish specific tasks.

- Prepare technicians with a broad working knowledge and set of skills to efficiently and effectively repair systems, operate, maintain, and calibrate photonic subsystems, and integrate those subsystems into full systems.

- Create an academic offering with innovative techniques and tools and with growth potential in order to address employment needs in Puerto Rico and the needs of a specialized workforces for industries in Puerto Rico and the United States.

The academic model to be followed is on-site class with a strong laboratory component. Laboratories are held at the REdI (Red Empresarial de Innovación) building at the Barceloneta Science Park, where PRPI facilities comprise approximately 3200 square feet. In addition to equipment purchased under New Horizons, the laboratory was already substantially equipped with funding from The Puerto Rico Science, Technology, and Research Trust (PRST) in 20132014.

\subsection{Graduate Profile}

The Certificate in Photonics \& Lasers Technical Specialist Program will form technicians with theoretical, methodological, and practical knowledge to participate in the operation, interface, integration, diagnosis, maintenance, and repair of optical, photonic, and laser stand-alone systems and of subsystems where photonics is an enabling technology. The graduates of this program will have the following competences:

\section{Cognitive Competences}

- Understand why some lasers are appropriate for certain applications and identify which laser systems are used in various technology areas. 
- Recognize the importance of laser manuals and specification sheets in the correct and safe use of laser and photonic equipment and devices.

- Describe what are the facility requirements, utility services and safety requirements for installing a commercially available laser system in a commercial, laboratory, or industrial setting.

- Understand the integration of photonics techniques into research, manufacturing, measurement, and communication applications.

- Evaluate information and its sources critically and incorporate selected information into the work done in the course.

2. Technical Competences

- Comply and follow all the safety guidelines when working with lasers and optical systems.

- Set up and align a laser or optical system according to given manufacturing specifications in order to perform a specific task.

- Follow proper methods for optical inspection and cleaning.

- Measure the output characteristics of a laser.

- Engage in basic troubleshooting of laser equipment.

- Demonstrate the integrations of electronics, optics, and photonics in real-life technological applications.

- Select and access needed information effectively and efficiently.

3. Affective Competences

- Value the importance of optics, photonics, and lasers in present day research and technological applications.

- Recognize applications of the specific types of lasers studied to different industries and the used of these systems to address the needs of society at large.

- Work in teams, learn from others, accomplish given goals, lead, and negotiate.

- Understand the importance of the appropriate use of information sources and the ethical, legal, and economic issues surrounding information.

\section{CHALlengeS}

The Photonics STEM field in Puerto Rico is affected by three main broadening participation (BP) challenges. First, the current economic situation in Puerto Rico prevents many prospective students from pursuing an education since they cannot pay for it themselves, often do not qualify for or have consumed their federal aid, and they fear incurring debt. Second, cultural and language barriers prevent many from even considering applying to a university or college in the continental US. Third, the challenge faced by the photonics industry worldwide that is growing at a faster pace than the number of professionals being trained in the field, and thus requires expanded education and training opportunities.

The New Horizons program is designed to address these challenges in the following ways:

1. Development of an optics curriculum based on industry-required knowledge and skillsets.

2. An integrated internship program during which each student will spend eight (8) weeks working for a company that may be the student's future employer.

3. Laboratories equipped with state-of-the-art equipment specified in consultation with local and national industries.

4. Bi-lingual instruction, in which classes are taught in Spanish and all written materials are in English.

Other issues that arise will require future efforts and results. High school graduates generally avoid certificate programs, as the idea of a degree, be it 2-year or 4-year, is less daunting for those who have not yet incurred family responsibilities 
or debts. For this reason, the AAS program approval, and then the transition of our program from a 1-year Certificate to a 2-year AAS is vital. The certificate will still be available, albeit with some modifications, for those who do not wish to complete the general education requirements for the AAS degree. Our current student demographic is represented by people who have been out of college for some years (some, 20 or more years). These students have a difficult time reestablishing (or in fact establishing for the first time) study habits. We are working hard to develop support systems, as well as in-class pedagogic methods that better suit these students. Finally, there having been no photonics jobs in Puerto Rico, students are justifiably skeptical about their career prospects. We are working with our employer community to develop a database of jobs, and within the program we work to make sure that all students can visit at least one employer associated with PRPI during their studies.

The economic situation in Puerto Rico cannot be neglected in this analysis. Puerto Rico population is declining as people look for opportunity in the US mainland. The departure of young people, unemployed people with families and the need for new jobs, and professionals seeking better opportunity and stability has an especially large impact on universities.

\section{CURRICULUM}

Table 1. PRPI New Horizons 1-year Curriculum

\begin{tabular}{|l|l|c|}
\hline Term & \multicolumn{1}{|c|}{ Course Title } & Credits \\
\hline 1 & Introductory English Language & 3 \\
\hline 1 & Mathematics for Technicians & 5 \\
\hline 1 & Fundamentals of Light and Lasers & 3 \\
\hline 2 & Introduction to Entrepreneurship & 4 \\
\hline 2 & Laser Systems and Applications I & 5 \\
\hline 2 & Electronics for Optics and Photonics I & 5 \\
\hline 3 & Industry Technical Internship & 3 \\
\hline 4 & Laser Systems and Applications II & 5 \\
\hline 4 & Photonic-Enabled Technologies & 4 \\
\hline 4 & Electronics for Optics and Photonics II & 5 \\
\hline
\end{tabular}

Table 1 presents the one-year (four quarters) curriculum plan for New Horizons. Courses are for-credit, so that the credential earned is stackable, and we anticipate approval of our Associate Degree program in the very near future. Once approved, students who wish to continue to an AAS degree need only complete the general education component of the degree, which will require 1-2 semesters. We will be developing elective courses for the AAS degree as well.

The curriculum is notable in that not only does it contain the four basic optics, lasers and photonics courses, but three innovative additional elements:

1. Two electronics courses - many photonics Certificate and AAS degrees are built on electronics programs. As PRPI started with photonics, we offer the generally-required electronics background as part of the Certificate.

2. Industry internships - students will spend their third of the four terms (eight weeks) working full time as industry technicians. The internship has multiple purposes. First, students will get first-hand work experience as part of their education, and industry mentor/supervisor surveys will help students to improve their soft skills and for PRPI to improve the students' preparation, both for internships and eventual employment. Second, companies will have the opportunity to "field test" PRPI students, considering them for eventual employment. Third, industries and PRPI will maintain constant communication on knowledge and skillset needs. And fourth, PRPI will be able to modify and adjust its offerings to align better with industry needs. 
3. Entrepreneurship - Entrepreneurship courses are generally not a part of technical education. Yet we see myriad opportunities for entrepreneurial-minded students to apply their newly developed skills in lasers and photonics to starting new companies.

\section{FUTURE EXPECTATIONS AND DEVELOPMENTS}

As mentioned, the PRPI Certificate as a Laser and Photonics Technical Specialist will eventually morph into an Associate in Applied Science Degree in Engineering Technology in Photonics and Lasers. We anticipate approval of this proposed degree in the very near future from the Puerto Rico Council of Higher Education. Following that, we have developing ideas for higher degrees.

Although a Bachelor Degree is a tempting prospect, the lack of an engineering school at our university is a major obstacle. We hope to begin a project with local engineering colleges, starting with our sister university, the University of Turabo, to offer a photonics professional certificate (or perhaps, if it is workable, a minor) for engineering majors. Later, through a consortium of aerospace universities in Puerto Rico, and organized by the local Aerospace Manufacturing Community, we hope to benefit from crossover credits between universities in order to offer photonics to any and all STEM majors in Puerto Rico.

Finally, we hope to benefit from the dearth of photonics technology programs nationally and internationally by attracting students to study photonics in Puerto Rico.

\section{REFERENCES}

[1] Cole, D. and Espinoza, A., "Examining the Academic Success of Latino Students in Science Technology Engineering and Mathematics (STEM) Majors," J. Coll. Student Dev. 49(4), 285-300 (2008). DOI: 10.1353/csd.0.0018. 